\title{
Flood Risk Assessment and Quantification at the Community and Property Level in the
} State of Iowa

\author{
Enes Yildirim ${ }^{1}$, Craig Just ${ }^{1}$, Ibrahim Demir ${ }^{1}$
}

${ }^{1}$ Department of Civil and Environmental Engineering, University of Iowa, Iowa City, Iowa, US

Corresponding Author: Enes Yildirim, enes-yildirim@uiowa.edu

\begin{abstract}
Flood risk assessment contributes to identifying at-risk communities and supports mitigation decisions to maximize benefits from the investments. Large-scale risk assessments generate invaluable inputs for prioritizing regions for the distribution of limited resources. High-resolution flood maps and accurate parcel information are critical for flood risk analysis to generate reliable outcomes for planning, preparedness, and decision-making applications. Large-scale damage assessment studies in the United States often utilize the National Structure Inventory (NSI) or HAZUS default dataset, which results in inaccurate risk estimates due to the low geospatial accuracy of these datasets. On the other hand, some studies utilize higher resolution datasets, however they are limited to focus on small scales, for example, a city or a Hydrological United Code (HUC)-12 watershed. In this study, we collected extensive detailed flood maps and parcel datasets for many communities in Iowa to carry out a large-scale flood risk assessment. Highresolution flood maps and the most recent parcel information are collected to ensure the accuracy of risk products. The results indicate that the Eastern Iowa communities are prone to a higher risk of direct flood losses. Our model estimates nearly \$10 million in average annualized losses, particularly in large communities in the study region. The study highlights that existing risk products based on FEMA's flood risk output underestimate the flood loss, specifically in highly populated urban communities such as Bettendorf, Cedar Falls, Davenport, Dubuque, and Waterloo. Additionally, we propose a flood risk score methodology for two spatial scales (e.g., HUC-12 watershed, property) to prioritize regions and properties for mitigation purposes. Lastly, the watershed-scale study results are shared through a web-based platform to inform the decisionmakers and the public.
\end{abstract}

Keywords: flood loss, risk analysis, data analytics, web systems

This manuscript is an EarthArXiv preprint and has been submitted for possible publication in the Science of the Total Environmentjournal. Please note that this has not been peer-reviewed before and is currently undergoing peer review for the first time. Subsequent versions of this manuscriptmay have slightly different content. If accepted, the final version of this manuscript will beavailable via the 'Peer-reviewed publication DOI' link on this webpage. Please feel free to contact the authors; we welcome anys feedback. 


\section{Introduction}

Flooding causes heavy economic losses on properties in urban areas across the world. In the United States, more than $\$ 39$ billion was paid for flood insurance claims between 1984 to 2020, and nearly 41 million people live within the 100-year flood zone (FEMA, 2020; Wing et al., 2018). Flooding and severe storms have the highest proportion of presidential disaster declarations in the U.S. (FEMA, 2020). Every year, the Federal Emergency Management Agency (FEMA) provides grant opportunities for vulnerable communities through various mitigation programs such as Hazard Mitigation Grant Program (HMGP), Flood Mitigation Assistant (FMA) Program, and Building Resilient Infrastructure \& Communities (BRIC) to reduce flooding impact (FEMA, 2020). Recent studies indicate that the probability and magnitude of flood events are increasing in many regions in the US (Barth et al., 2018; Musselman et al., 2018; Mallakpour and Villarini, 2015; Slater and Villarini, 2016, Paprotny et al., 2018). Along with the probability and magnitude of an event, studies reveal that human interaction and climate trends contribute to the number of extreme flooding events. Rapid urbanization (Hodgkins et al., 2019), changing land use (Rogger et al., 2017), and shifting flooding patterns (Blöschl et al., 2017) are increasing urban flood risk for communities. Understanding the risk is critical to take strategic mitigation measures to eliminate life losses and reduce economic impacts to create flood-resilient communities.

Many scientific studies and reports on flood resilience have been published in the last few decades (WMO, 2020; World Bank, 2013; UNISDR, 2015). Flood resilience is defined as a community's ability to accommodate disruptions (e.g., geophysical, economic, social) as well as resist, absorb, or restore from disruptions (e.g., floods, storms, earthquakes) in a short period of time (Sayers et al., 2013).In many developed countries, federal and local authorities support flood resilience research and applications (DHS, 2019; DEFRA, 2016; CSIRO, 2020; Gupta, 2020). An integrated resilience plan can be created with a multi-disciplinary approach, including economic, environmental, social, and governance aspects of flooding (Schelfaut et al., 2011, Demir et al., 2018). A resilience plan can also be enhanced with individual studies by examining environmental (Wang et al., 2019), economic (Hallegatte, 2014), social (Cutter et al., 2018), and governance (Vitale et al., 2018) aspects of the phenomena. Flood risk studies generate valuable inputs to contribute to flood resilience plans for communities in flood-prone regions (Waghwala et al., 2019) by examining property losses (Nofal et al., 2020), agricultural losses (Tapia-Silva et al., 2011), transportation disruption (Suarez, 2005), what-if analysis (Lawrence et al., 2013), and many other related elements. Web-based systems are critical in communicating community level studies on flood risk (Teague et al., 2021), water quality (Demir et al., 2009), and sedimentation (Xu et al., 2020) to many stakeholders, and supporting participatory decision making (Ewing and Demir, 2021).

\subsection{Flood Risk Assessment}

Flood risk assessment is critical to support various decisions such as selecting a mitigation option (Merz and Thieken, 2004), determining design level for a mitigation application (Morita, 2008), 
and specific implementations like constructing a reservoir (Sumi, 2008), managing a reservoir (Huang et al., 2018), and designing a levee (Jonkman and Schweckendiek, 2015). Besides, the feasibility of the mitigation practices can not be assessed without flood risk research and previous flood event data (Sebastian, 2016; Haltas et al., 2021, Yildirim and Demir, 2021). A flood resilience plan for a community can be enhanced by the contribution of a detailed flood risk analysis. However, quantifying flood risk is a challenge due to the complexity of estimating all the consequences of a disaster event. Various infrastructures may be affected during a flood event, such as public and private properties, businesses, transportation, and essential facilities. Particularly, estimation of indirect losses for an impacted region is critical because of the longterm effects of an event (Merz et al., 2011), data confidentiality (e.g., health, insurance expenses) (Andre et al., 2013), and challenges of assessing neighboring regions of the affected area (Merz et al., 2010). A detailed direct flood loss assessment can reflect the level of an impact for a potential flood event.

Decision-makers often utilize direct flood damage and loss estimates to determine at-risk communities, develop emergency plans, and select mitigation measures to reduce flooding impact (Yildirim and Demir, 2019). Damage functions (Yildirim, 2017) and fragility curves (Gouldby et al., 2008) are frequently employed analytical approaches to quantify direct flood losses. On the other hand, high-quality datasets for research and community studies (Ebert-Uphoff et al., 2017) are essential to generate more reliable assessments. One of the vital data needs is high-resolution flood inundation maps that are significant to couple with damage functions for estimating loss more accurately. Well-structured and spatially accurate property information is also essential to utilize in flood risk assessment. After the data requirements are satisfied in the assessment, the deliverables can be improved using visualization techniques, and scoring or indexing methodologies. Prioritizing regions can be used to allocate limited resources more effectively for mitigation applications.

\subsection{Flood Risk Quantification and Scoring}

Flood risk scoring or indexing is one of the most frequent methods for communicating flood risk assessment products. Risk scoring allows for prioritizing regions at-risk, updating emergency operation plans, improving hazard mitigation plans, educating homeowners/renters, and facilitating community-level risk communication (FEMA, 2021). Several studies have proposed flood risk score methodologies for classifying at-risk properties and communities (Martínez-Graña et al., 2016). These studies utilized the scoring methodologies based on various types of inputs such as geomorphological features (Martínez-Graña et al., 2016), risk of essential facilities (Phongsapan et al., 2019), hydrological parameters (Khan et al., 2019; Gao et al., 2020), flood zone (Luu et al., 2020; Eichholtz et al., 2019), and inundation depth (Phillips et al., 2017; Garvin et al., 2016). The data availability can be a significant obstacle for flood risk scoring (Emanuelsson et al., 2014). Studies may rely on detailed hydraulic flood models to conduct flood score risk, and others may use comprehensive datasets for critical infrastructure or demographics to score the risk. However, a flood risk score enhanced with mitigation input can be more helpful for loss reduction. 
To support the National Flood Insurance Program (NFIP), FEMA released a product called Risk Rating 2.0, a decision guidance tool for risk scoring considering the mitigation (FEMA, 2021). The flood risk score can generate valuable information in property and community scales for allocating resources to reduce flooding impact.

\subsection{Scope of the Study}

Quantifying flood risk is a challenging task for decision-makers due to data availability and required expertise in flood map modeling, geographic information systems (GIS), database management. Performing a large-scale risk analysis is also a demanding activity for decisionmakers to manage and analyze big data (e.g., state-wide flood maps, parcel information). The majority of the large-scale flood risk assessment studies deliver results at the census-block level that may not sufficiently support reliable mitigation decisions. However, a property-level detailed risk quantification generates more reliable input for identifying at-risk properties and supporting mitigation decisions to reduce potential flood impacts. Thus, prioritizing the regions and properties can be accomplished by allocating limited resources (e.g., hazard mitigation, public assistance) to mitigate the effects of flooding.

This study presents an extensive flood risk assessment study for the state of Iowa and compares the state's flood risk with federal products such as flood risk maps, community resilience maps, and social vulnerability maps. Nearly 48,000 properties are assessed using more than 450 unique flood inundation scenario maps to conduct the risk assessment. The study compares the risk outputs with FEMA's latest risk analysis to investigate the current products' accuracy for the state. Also, community resilience and social vulnerability of the most impacted 20 census-blocks are given based on FEMA's National Risk Index (NRI) products. Watershed-scale results are shared through a web-based flood information system to inform decision-makers and the public. The study also proposes a flood risk score methodology at the property and watershed-level (hydrologic unit code (HUC)-12), considering the data challenges and limitations in the literature. The flood risk score is generated using inundation depth, flood zone, average mitigation costs, average annualized losses regarding probability-based flood scenarios for a property and a watershed-level. The risk score can be an input for mitigation decisions (i.e., buyout, dry floodproofing, sandbagging). Thus, the study's output can deliver insights into the communities' flood risk in the state and contribute to mitigation decisions (Sermet et al., 2020; Xu et al., 2020) to reduce future flood losses.

The study presents the overall methodology covering the study region, data sources, loss estimate methodology, and the flood risk score methodology in the following sections. Then, the results of the large-scale flood risk analysis and implementation of the flood risk score methodology are shared. Finally, key takeaways, challenges, and future work are given in the conclusion. 


\section{Methodology}

\subsection{Case Study}

Iowa has experienced several flooding events in major communities over the last three decades, such as flooding in 1993, 2001, 2008, 2014, 2016, and 2019 (Flood Factor, 2020; FEMA, 2020; Brakenridge, 2020; Flanagan, 2020). Since 2005, FEMA has supported communities in Iowa by funding \$1.57B for public assistance, \$145M for preparedness, and \$513M for mitigation purposes (FEMA, 2020). The U.S. Department of Housing and Urban Development sponsored the Iowa Watersheds Approach (IWA) project to mitigate flood damage and improve the resilience of the communities in the state (Weber et al., 2018). IWA is a five-year-long project started in January 2016 that involves multiple institutions (e.g., governmental, academic, municipal) collaborating to mitigate potential flooding impacts for select communities in Iowa (Rundhaug, 2018).

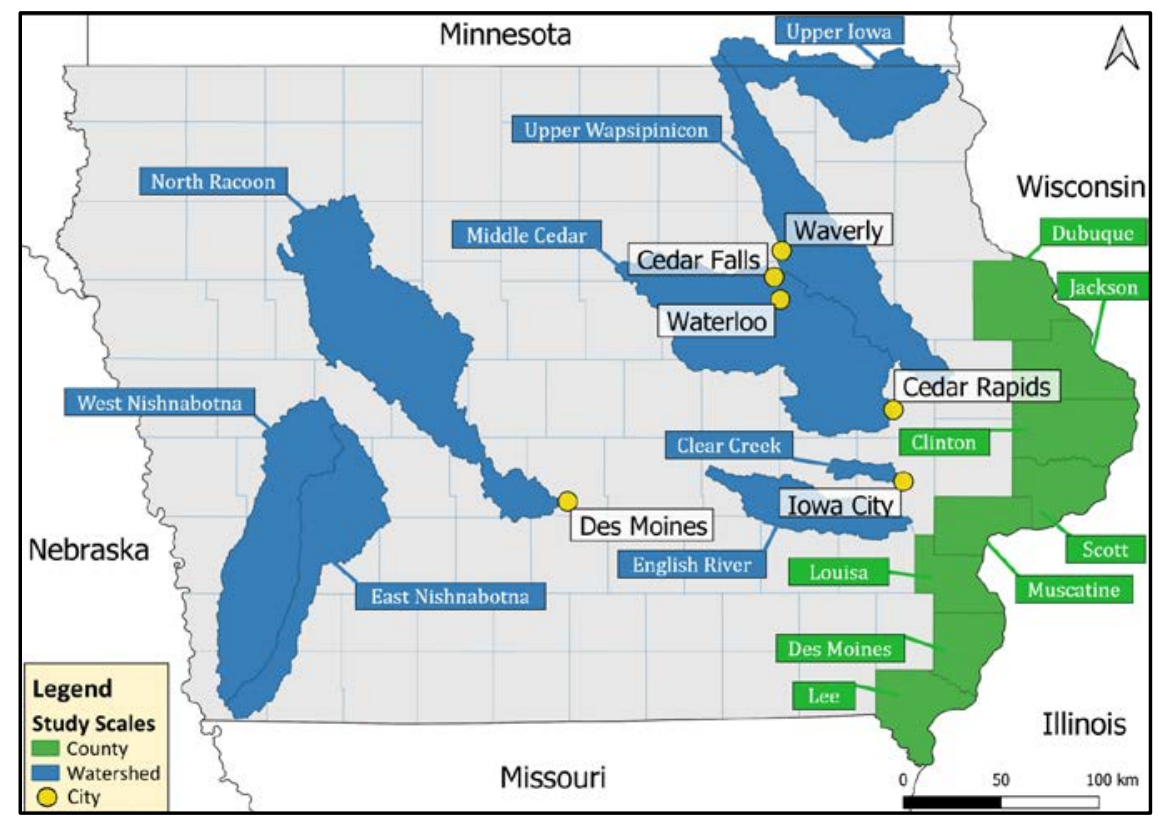

Figure 1. Study region for the flood risk assessment in Iowa

This study contributes to the Iowa Watersheds Approach project by delivering the watershedscale flood risk assessment in nine watersheds: Clear Creek, Dubuque Bee Branch, East Nishnabotna, English River, Middle Cedar, North Racoon, Upper Wapsipinicon, Upper Iowa, and West Nishnabotna. Over the last couple of decades, these watersheds have experienced several flooding events that severely impacted the communities in the region (FEMA, 2020). The region's major streams are the Cedar River, the Des Moines River, and the Iowa River that joins the Mississippi River. The region's landscape is heavily altered, primarily by agricultural practices and urban settlements that occupy \%87 of the state's land cover (Herringshaw et al., 2011). In addition to the watershed-scale focus, the study also investigates the flood risk of eight Iowa counties near shorelines along the Mississippi River (Clinton, Des Moines, Dubuque, Jackson, Lee, Louisa, Muscatine, and Scott counties) on the county-scale. Lastly, the city-scale risk assessment is carried 
out for Cedar Falls, Cedar Rapids, Des Moines, Iowa City, Waterloo, and Waverly. The study region on all scales is demonstrated in Figure 1. Figure 2 shows the population distribution across the state and the study region. The study region is selected to cover highly populated communities that are prone to significant flood events considering the region's experience of flooding events and the population.

\subsection{Data Collection}

The study utilizes various data sources such as parcel information, high-resolution (1-meter) flood inundation maps, flood damage functions, satellite imagery, and building footprint data. These datasets are acquired from multiple governmental, academic, and private institutions, including the Iowa Homeland Security Emergency Management Department (IHSEMD), the United States Army Corps of Engineers (USACE), the Iowa Flood Center (IFC), and county tax assessors. The PostgreSQL and PostGIS libraries are used to manage and process datasets on the server-side. Table 1 summarizes the physical information, population, and list of datasets that are utilized in this study. The study region covers more than half of the population of the state. The populations of the large communities are subtracted from the watershed population in the table.

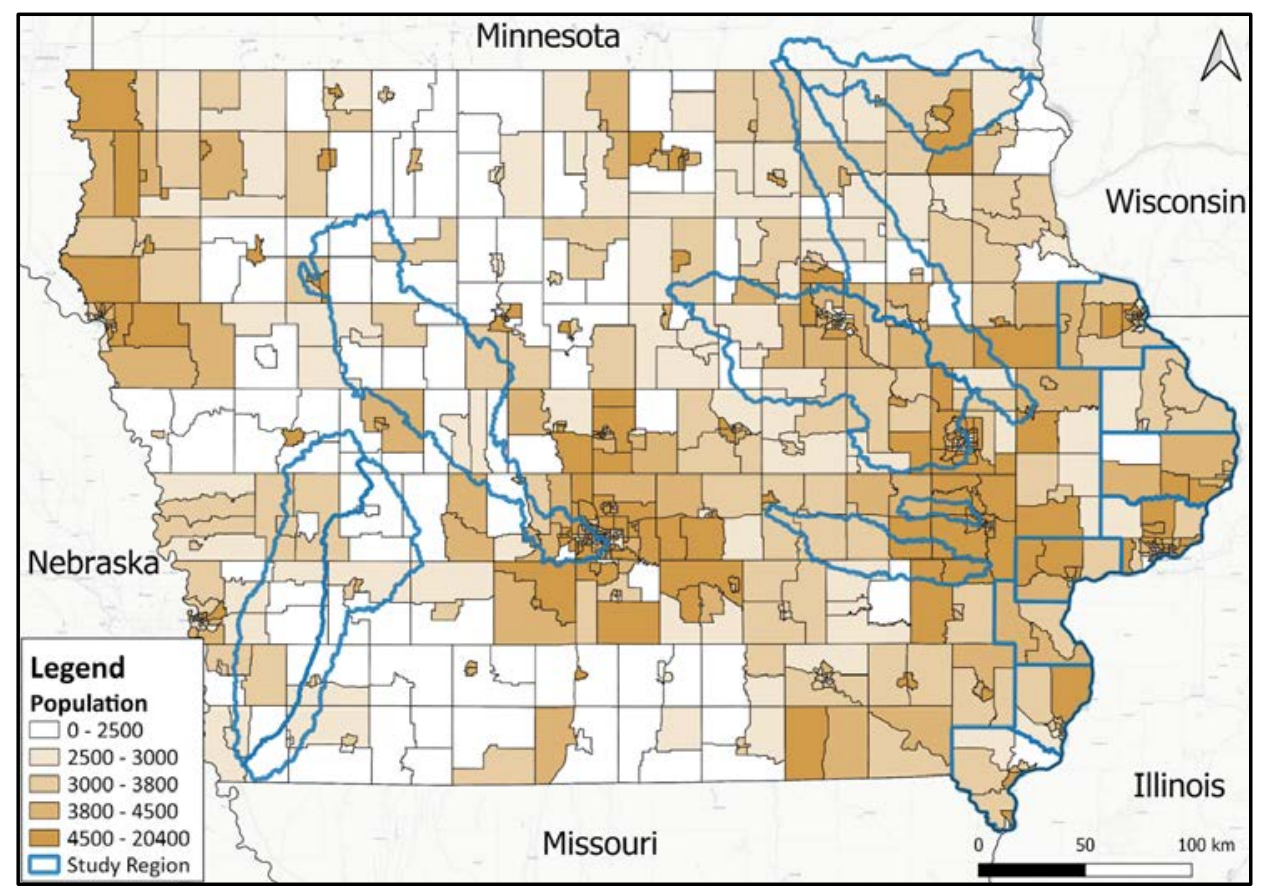

Figure 2. Population distribution in the State of Iowa (The U.S. Census Bureau, 2021)

The parcel information is collected from the county tax assessors for the county-scale and the city-scale assessments. The watershed-scale parcel data is collected during the IWA project. The parcel data's spatial coverage is validated for properties using Quantum Geographic Information System (QGIS) and satellite imagery data. The building footprint repository from Microsoft is used to estimate the square footage for the properties with no value recorded in the county-scale 
assessment. Then, structural values are estimated based on the square foot value for the properties on the county-scale.

The flood maps were acquired from the Iowa Flood Center, which developed state-wide highresolution flood inundation maps. Raster-based digital elevation models (DEMs) with a one-meter resolution are used to generate the flood maps (Gilles et al., 2012). The flood maps created in different probability are utilized in the study to analyze losses in a probabilistic approach. The flood maps based on 500-, 200-, 100-, 50-, 25-, 10-, 5-, and 2-year return period floods are used for the watershed-scale flood risk assessment. In the city-scale study, flood maps are created considering the United States Geological Survey (USGS) gauge location to reflect flood inundation at every half-foot of stage-height. The rating curves developed by the National Weather Service are employed to find corresponding stage-height flood maps for the probabilistic flood maps. These eight probability-based scenarios are used for other estimations in the study. The USACE provided the flood maps based on six probabilities in the county-scale risk assessment, namely 500-, 200-, 100-, 50-, 25-, and 10-year return period floods. The flood maps are handled in raster format in the PostgreSQL database.

Table 1. Data summary for flood maps and parcel information

\begin{tabular}{|c|c|c|c|c|c|c|}
\hline & Study Region & Population & $\begin{array}{c}\text { Area } \\
\text { (sq mi) }\end{array}$ & $\begin{array}{l}\text { Flood } \\
\text { Maps }\end{array}$ & $\begin{array}{l}\text { Number of } \\
\text { Properties }\end{array}$ & $\begin{array}{c}\text { Total Property } \\
\text { Value }\end{array}$ \\
\hline \multirow{6}{*}{ 晃 } & Cedar Falls & 40,983 & 30 & 50 & 546 & $\$ 244.0 \mathrm{M}$ \\
\hline & Cedar Rapids & 132,301 & 72 & 60 & 4,033 & $\$ 999.5 \mathrm{M}$ \\
\hline & Des Moines & 215,636 & 90 & 120 & 8,312 & $\$ 2,169.6 \mathrm{M}$ \\
\hline & Iowa City & 74,950 & 26 & 34 & 5,149 & $\$ 1,941.1 \mathrm{M}$ \\
\hline & \begin{tabular}{|l|} 
Waterloo \\
\end{tabular} & 67,912 & 63 & 60 & 7,201 & $\$ 1,563.7 \mathrm{M}$ \\
\hline & Waverly & 10,094 & 12 & 36 & 3,598 & $\$ 574.6 \mathrm{M}$ \\
\hline \multirow{8}{*}{ 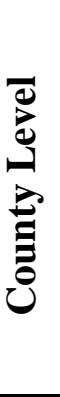 } & Clinton & 46,909 & 695 & 6 & 232 & $\$ 274.8 \mathrm{M}$ \\
\hline & Des Moines County & 39,386 & 517 & 6 & 171 & $\$ 116.6 \mathrm{M}$ \\
\hline & \begin{tabular}{|l} 
Dubuque \\
\end{tabular} & 96,982 & 608 & 6 & 103 & $\$ 228.1 \mathrm{M}$ \\
\hline & \begin{tabular}{|l} 
Jackson \\
\end{tabular} & 19,401 & 591 & 6 & 109 & $\$ 15.1 \mathrm{M}$ \\
\hline & \begin{tabular}{|l|} 
Lee \\
\end{tabular} & 34,227 & 517 & 6 & 175 & $\$ 197.6 \mathrm{M}$ \\
\hline & Louisa & 11,178 & 402 & 6 & 46 & $\$ 6.8 \mathrm{M}$ \\
\hline & Muscatine & 42,889 & 439 & 6 & 191 & $\$ 167.6 \mathrm{M}$ \\
\hline & Scott & 172,446 & 458 & 6 & 1,149 & $\$ 3,197.0 \mathrm{M}$ \\
\hline \multirow{8}{*}{ 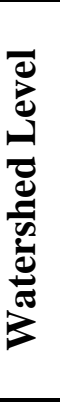 } & Clear Creek & 29,862 & 4227 & 8 & 672 & $\$ 658.3 \mathrm{M}$ \\
\hline & East Nishnabotna & 47,538 & 1,149 & 8 & 2,517 & $\$ 378.2 \mathrm{M}$ \\
\hline & English River & 21,700 & 639 & 8 & 213 & $\$ 156.0 \mathrm{M}$ \\
\hline & Middle Cedar & 55,440 & 6,710 & 8 & 6,269 & $\$ 2,159.1 \mathrm{M}$ \\
\hline & North Racoon & 146,610 & 2470 & 8 & 2,947 & $\$ 1,005.4 \mathrm{M}$ \\
\hline & Upper Iowa & 1,001 & 23,000 & 8 & 156 & $\$ 15.7 \mathrm{M}$ \\
\hline & Upper Wapsipinicon & 53,800 & 1,568 & 8 & 2,762 & $\$ 548.8 \mathrm{M}$ \\
\hline & West Nishnabotna & 1,652 & 47,858 & 8 & 1,112 & $\$ 165.8 \mathrm{M}$ \\
\hline
\end{tabular}


Flood damage function is the fundamental element for quantifying structural and content losses. These functions give the relationship between flood depth and the damage percentage of the structure and content of a building. In this study, damage functions that are developed by the USACE are employed for loss estimations. The study utilized 36 unique flood damage functions that are created based on occupancy types (e.g., residential, commercial, agricultural, industrial, public). The functions are stored in the PostgreSQL server for querying and estimating flood damage.

In order to compare flood risk products, the National Risk Index products, which are created by the Federal Emergency Management Agency (FEMA), are collected for the study region. The NRI contains annualized loss estimates, social vulnerability percentile (National and State), and community resilience percentile (National and State) at the census-block level. The primary objectives for the NRI are supporting emergency plans, prioritizing regions to allocate resources, and enhancing hazard mitigation plans (FEMA, 2021). The NRI products are utilized for comparing the average annualized loss estimates and querying social vulnerability and community resilience ranks for the most impacted 20 census-blocks in our study.

\subsection{Flood Risk Assessment}

Flood inundation depths, damage functions, structural and content values for properties are the primary inputs for the loss estimation analysis. The flood depths for properties are calculated based on flood rasters and point locations of the properties using the PostGIS library. First-floor heights are designated based on the occupancy type by employing the similar approach that HAZUS (Hazard United States) methodology uses (Vickery et al., 2006) due to the lack of direct first-floor height information on the parcel data. First-floor heights are subtracted from the inundation depths to get the actual flood depth for each property. Then, flood damage functions are used to assess structural and content loss ratios for each structure based on their occupancies. As demonstrated in Figure 3, damage functions provide structural or content loss percentages based on the flood depth for the occupancy type. Then loss ratios are multiplied with the structural and content values to reveal direct dollar losses, as shown in equation 1.

$$
\text { Direct Loss }=S x \frac{D P_{S}(d)}{100}+C x \frac{D P_{c}(d)}{100}
$$

where $D P_{s}(d)$ is the structural damage percentage as a function of depth (Figure 3); $D P_{c}(d)$ is the content damage percentage as a function of depth (Figure 3); $\mathrm{S}$ is the structural value for the property; $\mathrm{C}$ is the property's content value, which is estimated based on the occupancy type.

The analysis is carried out for over 450 unique flood maps within the study sites. An average annualized loss (AAL) is estimated for the study sites by using probability-based flood scenarios (e.g., $0.2 \%, 1 \%, 2 \%, 4 \%$, and $10 \%$ probabilities). Equation 2 shows the ALL estimation in the study. 


$$
\begin{aligned}
A A L= & L_{500} P_{500}+\left(P_{500}-P_{200}\right)\left(\frac{L_{500}+L_{200}}{2}\right)+\left(P_{200}-P_{100}\right)\left(\frac{L_{200}+L_{100}}{2}\right)+\cdots \\
& +\left(P_{100}-P_{50}\right)\left(\frac{L_{100}+L_{50}}{2}\right)+\left(P_{50}-P_{25}\right)\left(\frac{L_{50}+L_{25}}{2}\right)+\left(P_{25}-P_{10}\right)\left(\frac{L_{25}+L_{10}}{2}\right)
\end{aligned}
$$

where $\mathrm{L}$ is the probability-based direct loss such as $L_{500}$ stands for direct loss in 500-year flood; P is the probability of the scenario such as $P_{500}$ stands for the probability of a 500-year flood which is 0.02 .

The average annualized loss estimations are aggregated at census-block level and watershedlevel (HUC-12) for further analysis, such as flood risk scoring and flood risk map evaluation with the National Risk Index products. The PostgreSQL with the PostGIS library is utilized to calculate the required estimations explained above, and the results are stored on the server.
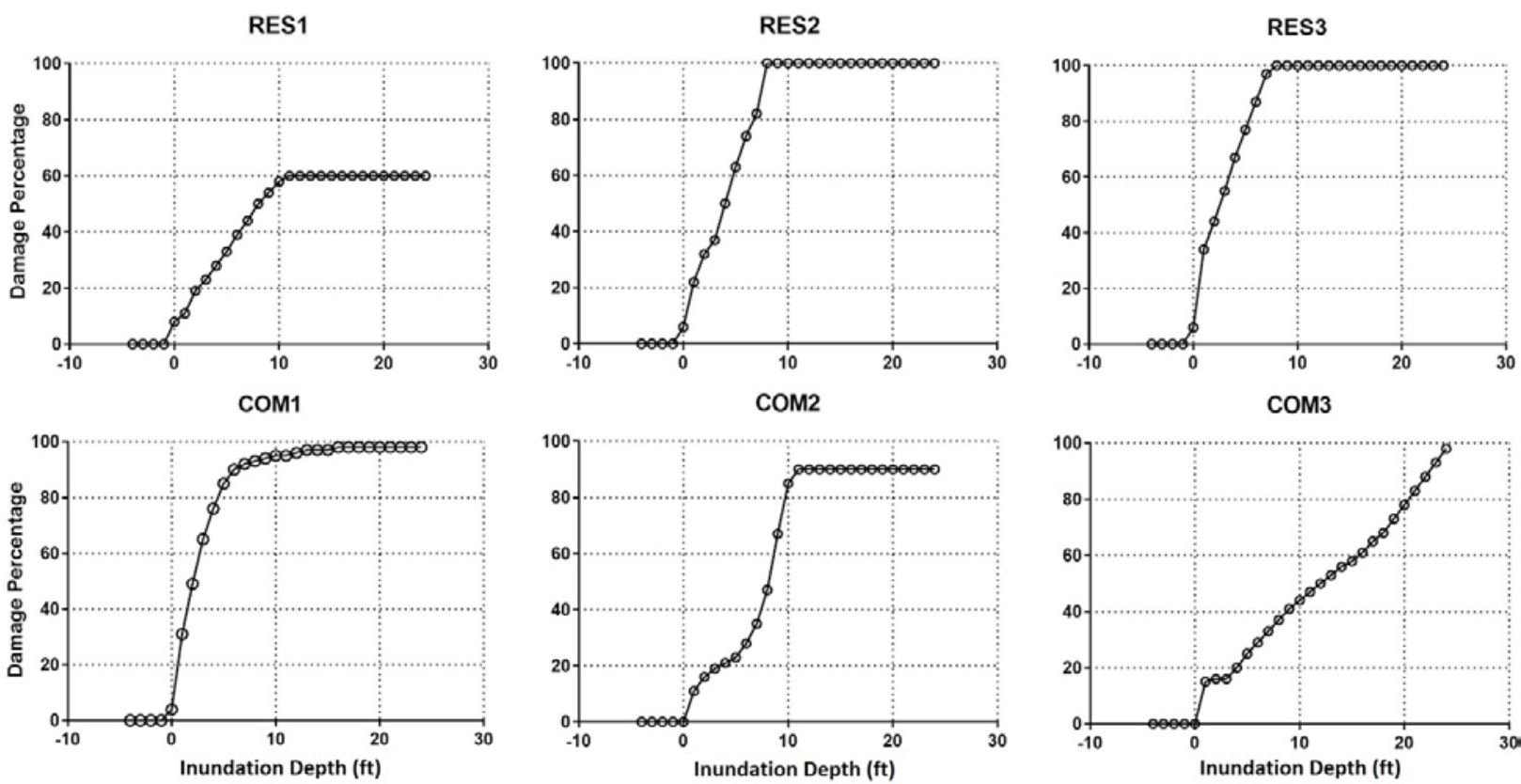

Figure 3. Damage functions for commercial and residential buildings (Yildirim and Demir, 2019)

\subsection{Flood Risk Score}

The flood risk score is generated at the property-level and watershed-level. At the property-level, the flood risk score mainly considers 30-year direct flood loss, which is estimated using the average annualized loss estimation. Besides, property values, flood depths, average mitigation design heights, and average mitigation costs are utilized in the flood risk score estimation. Mitigation design heights and costs are collected from FEMA's guidelines (FEMA, 2009) by considering different mitigation types (i.e., sandbagging, dry floodproofing, elevation, and relocation). Therefore, the score reflects the flood risk considering what level of mitigation may be required for the property. Four loss ratio groups are categorized based on the average mitigation costs and design heights. The flood risk score uses the following equation and the procedure shown in Figure 4. LR, PV, $D_{100}$, and $C_{e}$ represent loss ratio, property value, the flood depth at a 100-year flood 
scenario, and elevation cost for the structure, respectively. Each loss ratio group is normalized within their score groups, as shown in Figure 4.

In the watershed-level flood risk score, 30-year direct losses and property values are used to estimate the loss ratio. However, the ratio is not adjusted based on the mitigation cost or design level due to identifying an average mitigation cost, design height, and type for watershed scale. The ratio is normalized in the neighboring watersheds (HUC-12) from 1 to 10 to assign the score.

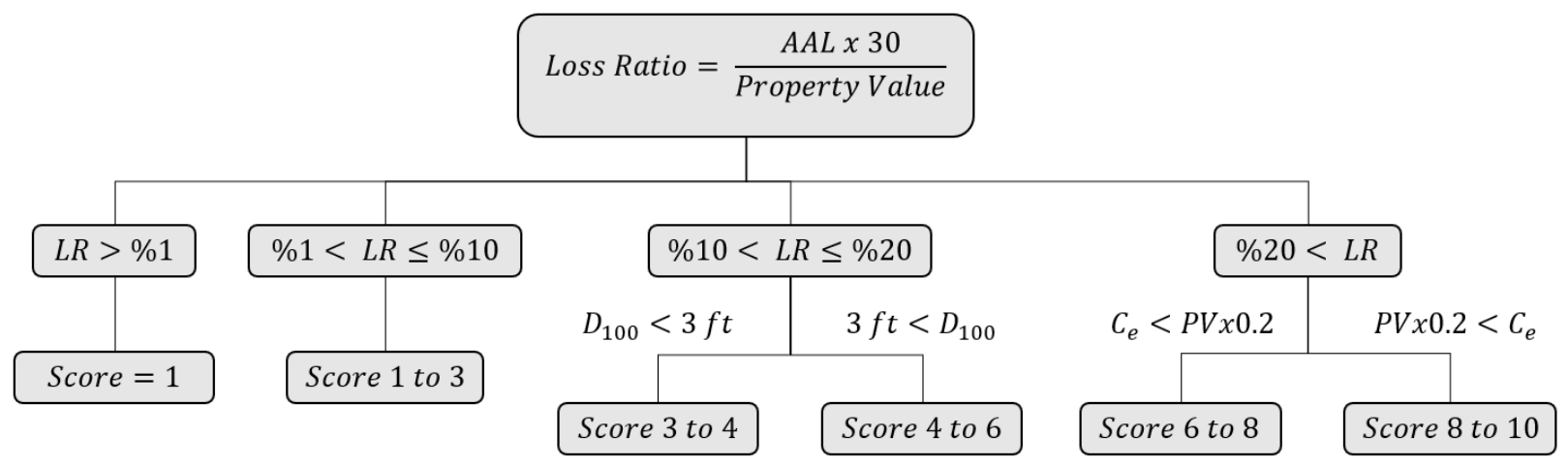

Figure 4. Flood risk score methodology in property-level

\subsection{Flood Risk Communication}

Web technologies improved significantly in recent decades providing desktop level capabilities for computation, analysis and visualization. Web systems have been used widely in client-side analysis and visualization of hydrological and disaster datasets for distributed computing (Agliamzanov et al., 2020), data exploration (Seo, et al., 2020), and geospatial data processing (Sit et al., 2019). Web systems facilitate communicating flood risk information with different stakeholders, which is critical for incorporating multiple parties into the decision making process. Community leaders, planners, decision-makers, and the public can be informed through web systems to understand risk, vulnerable zones, and potential damage from a flooding event.

In this study, scenario-based damage maps are generated and converted to Keyhole Markup Language (KML) format for easy delivery on a web-based system. HUC-8, HUC-12, and propertylevel damage maps are shared through a web system for visualizing the risk maps in multiple geospatial scopes. The analysis results of this study are integrated to the Iowa Watershed Approach Information System (IWAIS). The real-time stream gauge data and flood forecasting from the national and academic institutions are also hosted at the IWAIS for decision support purposes (Weber et al., 2018).

\section{Results \& Discussions}

In this study, flood risk assessments are carried out for nearly 48,000 properties in the study region. An average annualized loss (AAL) is estimated for each property using probability-based scenarios. Then the ALLs are aggregated at the census-block level to share the outcomes and compare them with federal risk and vulnerability assessments such as FEMA flood risk, social 
vulnerability, and community resilience indexing products. In Table 2, average annualized loss estimates are shared at the city, county, and watershed scales. The parcel information processed in the study does not cover most public buildings, critical infrastructures, and utilities. The county tax assessors do not evaluate properties that have tax-exempt eligibility. Therefore, there is no structural value or content value recorded for tax purposes for those structures. The output of the assessment reflects the direct loss estimates based on the structural and content value. In the following sections, we present the flood risk outcomes for each scale in the study and evaluate the risk results by comparing the National Risk Index outputs. At the end of the section, the flood risk score application is presented with a case study for the Middle Cedar watershed and Cedar Rapids city.

Table 2. Annualized loss estimates and number of impacted properties in the study sites

\begin{tabular}{|c|c|c|c|}
\hline & Study Region & $\begin{array}{c}\text { Annualized } \\
\text { Loss }\end{array}$ & $\begin{array}{c}\text { Affected } \\
\text { Properties }\end{array}$ \\
\hline \multirow{6}{*}{\begin{tabular}{l}
$\frac{\mathscr{U}}{\tilde{J}}$ \\
$\omega$ \\
\multirow{2}{*}{}
\end{tabular}} & Cedar Falls & $\$ 0.56 \mathrm{M}$ & 370 \\
\hline & Cedar Rapids & $\$ 1.96 \mathrm{M}$ & 2,480 \\
\hline & Des Moines & $\$ 1.02 \mathrm{M}$ & 499 \\
\hline & Iowa City & $\$ 0.98 \mathrm{M}$ & 4,461 \\
\hline & Waterloo & $\$ 1.63 \mathrm{M}$ & 5,521 \\
\hline & Waverly & $\$ 63 \mathrm{~K}$ & 268 \\
\hline \multirow{8}{*}{ 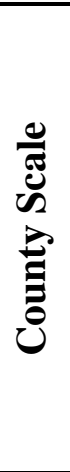 } & Clinton & $\$ 367 \mathrm{~K}$ & 229 \\
\hline & Des Moines County & $\$ 1.00 \mathrm{M}$ & 169 \\
\hline & Dubuque & $\$ 0.88 \mathrm{M}$ & 101 \\
\hline & Jackson & $\$ 73 \mathrm{~K}$ & 105 \\
\hline & Lee & $\$ 186 \mathrm{~K}$ & 170 \\
\hline & Louisa & $\$ 27 \mathrm{~K}$ & 44 \\
\hline & Muscatine & $\$ 0.54 \mathrm{M}$ & 189 \\
\hline & Scott & $\$ 3.9 \mathrm{M}$ & 1,109 \\
\hline \multirow{8}{*}{ 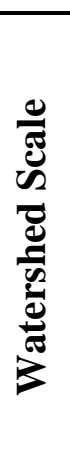 } & Clear Creek & $\$ 12 \mathrm{~K}$ & 55 \\
\hline & East Nishnabotna & $\$ 73 \mathrm{~K}$ & 669 \\
\hline & English River & $\$ 1 \mathrm{~K}$ & 8 \\
\hline & Middle Cedar & $\$ 3.1 \mathrm{M}$ & 2,030 \\
\hline & North Racoon & $\$ 28 \mathrm{~K}$ & 75 \\
\hline & Upper Iowa & $\$ 1 \mathrm{~K}$ & 4 \\
\hline & Upper Wapsipinicon & $\$ 98 \mathrm{~K}$ & 262 \\
\hline & West Nishnabotna & $\$ 35 \mathrm{~K}$ & 49 \\
\hline
\end{tabular}




\subsection{Flood Risk Assessment}

The results suggest that 18,867 properties are identified in the flood risk zone (500-year) out of 47,663 properties within the study sites. Middle Cedar is the most vulnerable in the watershedscale study, with an estimated \$3.1 million average annualized loss. The highest number of exposed properties is also estimated for the Middle Cedar watershed. 2,030 impacted properties are identified in the watershed, including all damage levels from minor to major levels. Based on the available dataset in the study, the least impacted watersheds are English Creek and Upper Iowa. On the county-scale, the study was conducted in eight jurisdictions along the Mississippi River (Des Moines, Dubuque, Jackson, Lee, Louisa, Muscatine, Scott). Scott County is the most vulnerable region with an estimated average annualized loss of \$3.9 million. The large portion of the loss is estimated for the city of Davenport within the county. In city-scale assessment, Waterloo has the highest average annualized loss with \$1.63 million and 5,521 impacted properties. The assessment shows that Waterloo has the highest number of affected properties compared to other communities in study for city-scale.
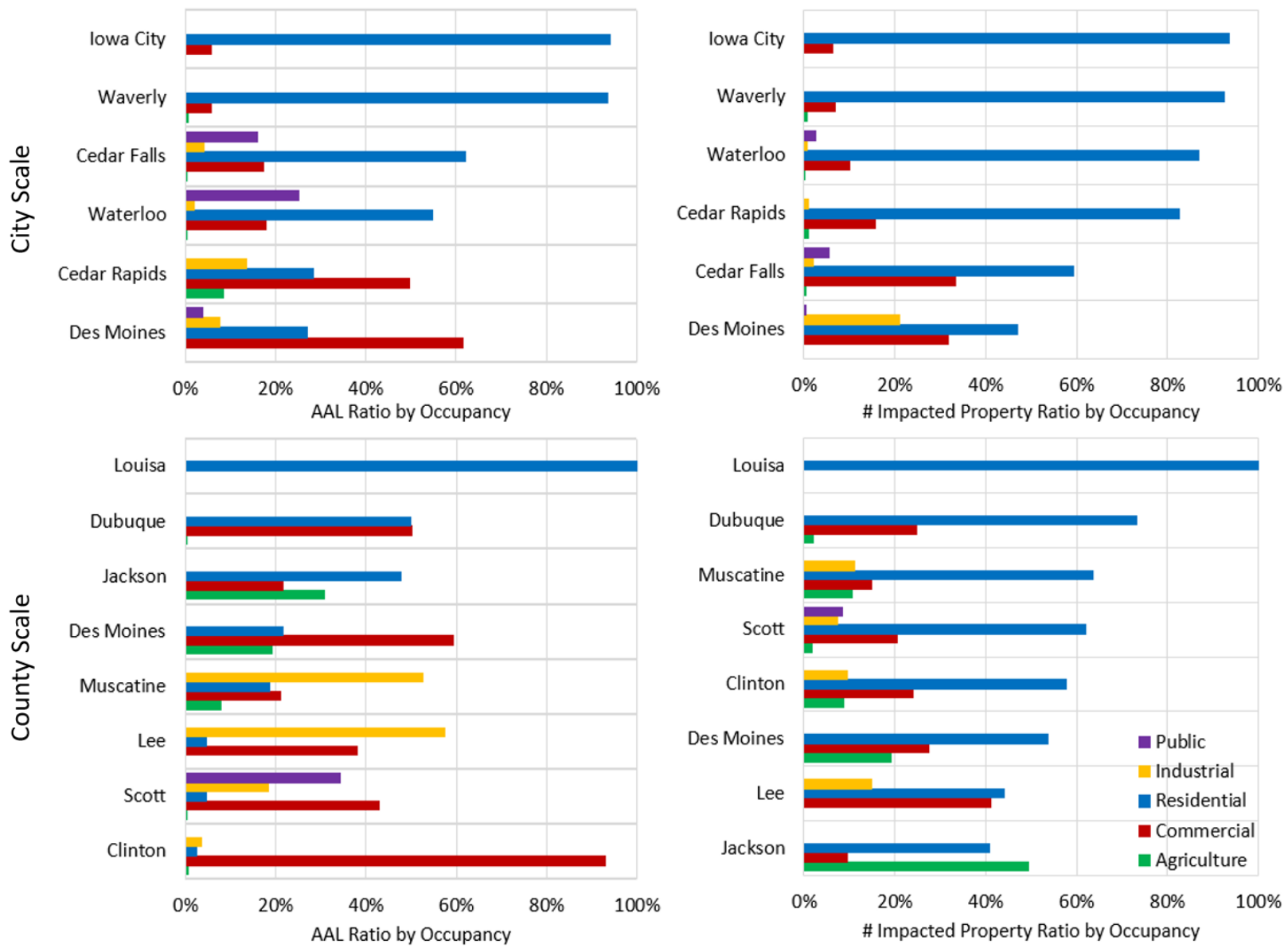

Figure 5. Occupancy distribution of ALLs (left) and number of impacted properties (right)

a watershed-scale assessment, the impacted properties are predominantly residential in terms of estimated average annualized loss and the number of affected properties. The flood exposure 
for other occupancy types is observed in other spatial scales. On the county-scale, most of the annualized loss is estimated for commercial or industrial properties. Louisa County is one of the outliers where residential properties are solely impacted. Overall, non-residential property damage was greater on a county-by-county basis, but the number of exposed residential properties was highest in all counties except Jackson.In Jackson County, agricultural facilities are affected more than other regions in terms of average annualized losses and the number of impacted structures. In Clinton County, over 90\% of the losses are estimated for commercial properties. Despite the number of impacted commercial properties being lower than other occupancies, Clinton County can be considered an outlier due to prevailing commercial property losses.

Considering the major cities in the study region, Iowa City is the most susceptible city concerning residential flood exposure. Although the residential impact is also primarily higher than different occupancy types in Cedar Falls and Waterloo, commercial flood impact is also substantially high in these communities. Based on the available data, Davenport has the highest public building exposure due to flooding compared to other cities. Commercial flood losses are the highest in Des Moines, Cedar Rapids, and Bettendorf. Figure 5 provides more details about the flood exposure percentage of dollar loss (left) and the number of impacted properties (right) regarding occupancy type. Davenport is estimated with the highest dollar loss per capita in the community-level assessment, which indicates the higher vulnerability of commercial and industrial properties in the city. The dollar loss per capita for most studied communities shows a similar ratio except Des Moines, which has the lowest loss per capita. Figure 6 demonstrates the estimated average annualized loss and population of major communities. City boundaries are considered to summarize the AALs and the population.

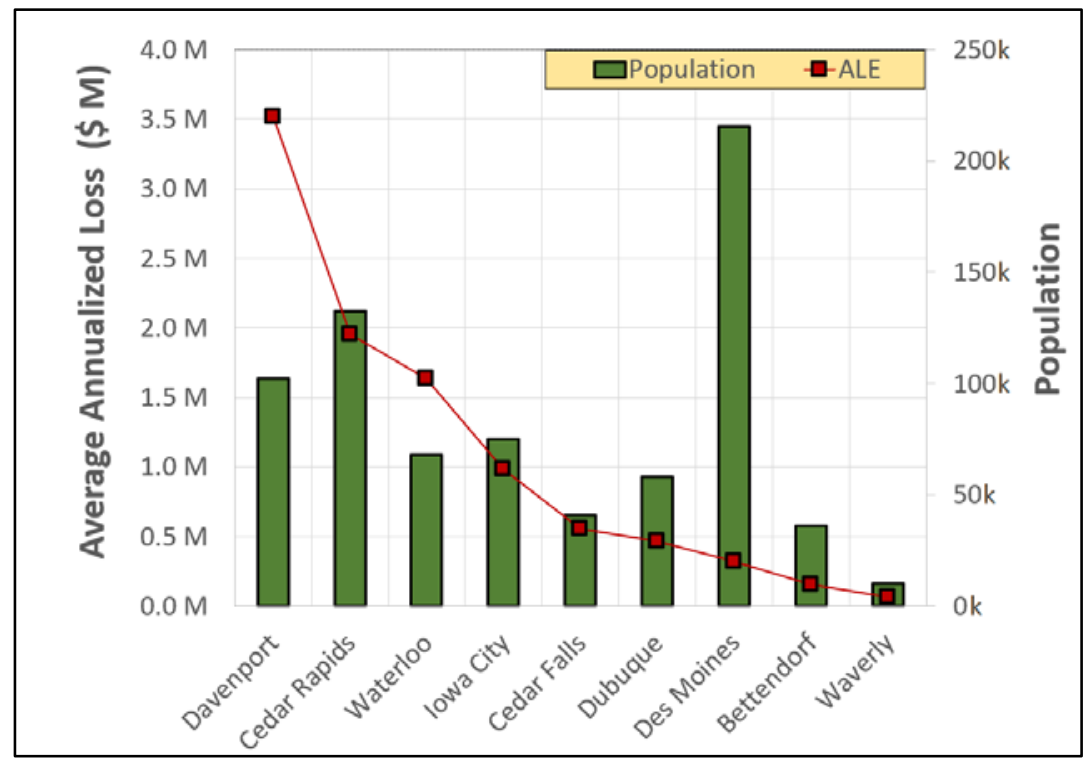

Figure 6. Average annualized loss (AAL) estimates and population of major communities 
The watershed-scale flood risk assessment is made available to decision-makers and the public through the Iowa Watershed Approach information system (https://iwa.iowawis.org) to improve the accessibility of the analysis. The Google Maps JavaScript Application Programming Interface (API) is utilized for visualization purposes. The system is an intuitive map-based environment for users to discover flood risk in the study regions. The results are shared at a watershed level (HUC8) and a property level. Figure 7 and Figure 8 indicate that flood risk assessments for the Middle Cedar watershed and the property-level loss summary are given, respectively.

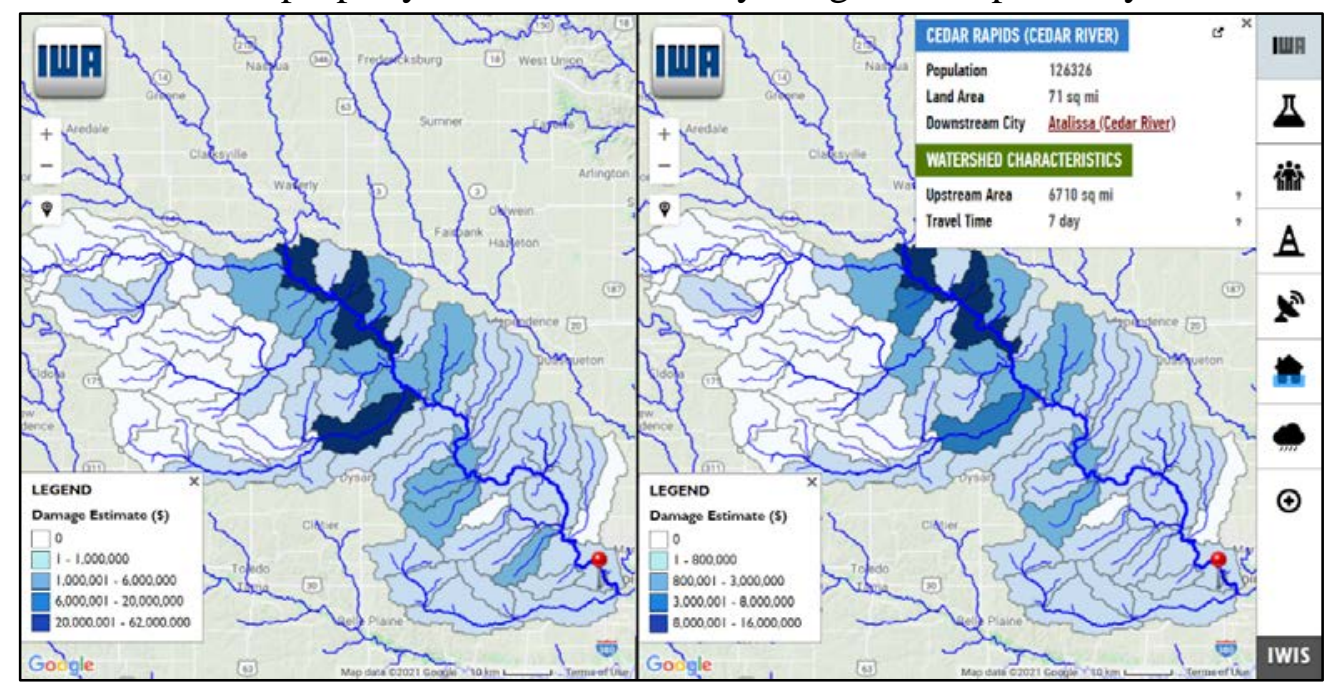

Figure 7. Middle Cedar watershed flood loss maps for 500-yr (left) and 100-yr (right) scenarios

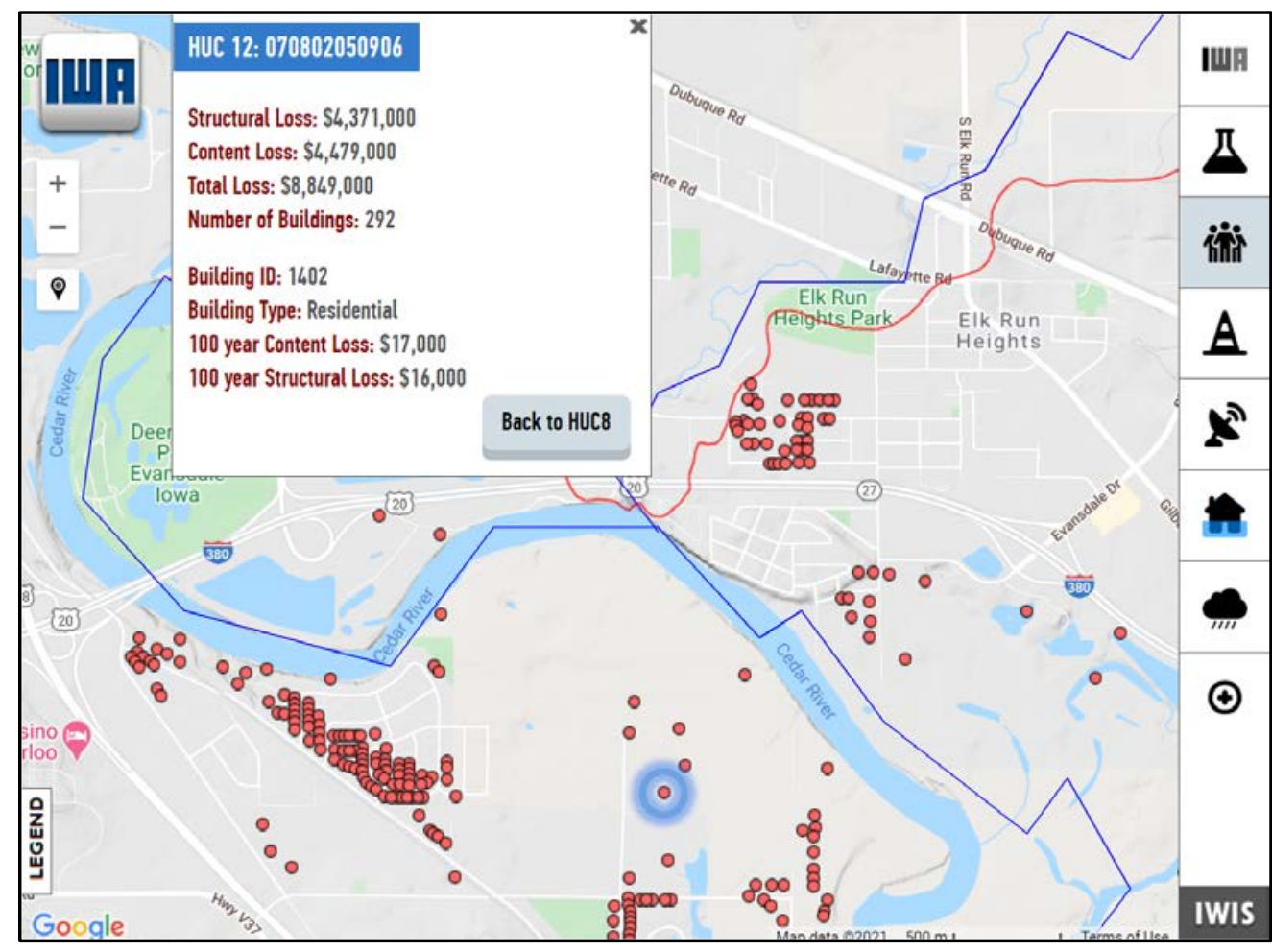

Figure 8. Property-level flood loss visualization at the HUC12 level 


\subsection{Flood Risk Score}

The flood risk score is generated for two spatial levels, property-level and watershed-level, within the range of 1 to 10. A higher score indicates a high risk of flooding with costly mitigation. As a case study, the flood risk score is applied in Cedar Rapids at the property-level, and Middle Cedar at the watershed-level demonstrated in Figures 9 and 10. The main goal for the flood risk score is to improve the risk products' accessability, prioritize regions or structures for mitigation, and support mitigation decisions. The flood risk score is generated using 30-year direct flood loss based on the average annualized loss estimation, property values, flood depth, mitigation costs, and design levels. Property-level flood risk scores can be used in structure-specific mitigation decision processes. The risk score delivers the flood impact level and reflects to what extent the property needs a mitigation application because of the relevant inputs in the scoring methodology. For instance, design heights and flood depts are critical to select mitigation methods for a property based on FEMA's guidelines. On the other hand, the watershed-level flood risk score helps identify regions that experience frequent flood loss. Therefore, regions with recurring flood damage can be prioritized to reduce future impact. Overall, the flood risk score can be a helpful input for decisionmakers and the public to take mitigation measures to reduce flooding impacts. Due to the limited resources, prioritizing is critical to locate the most vulnerable structures and to maximize the benefits of the mitigation efforts.

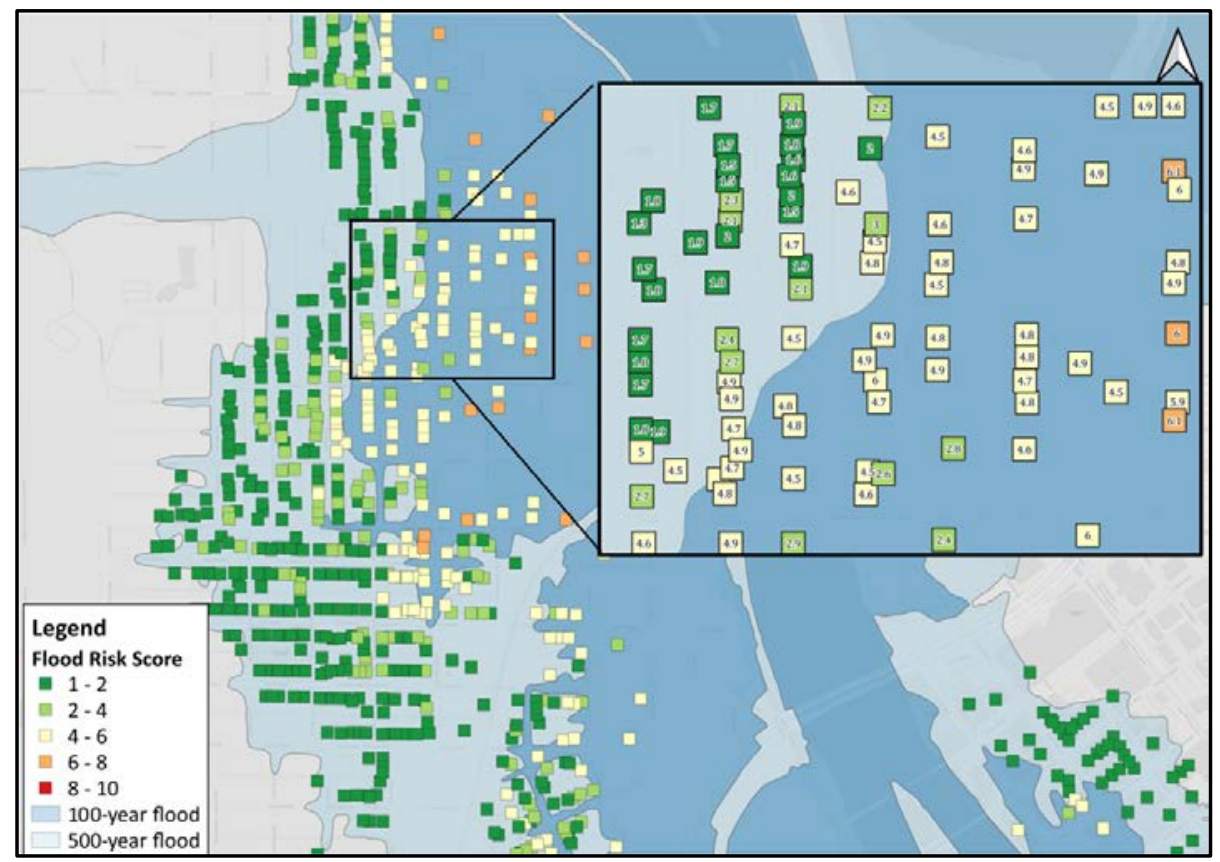

Figure 9. Property-level flood risk score for properties in Cedar Rapids

\subsection{Comparison to National Risk Index}

FEMA conducted disaster risk assessments considering multiple disaster types on a national scale and shared the National Risk Index (NRI) products for researchers and the public (FEMA, 2021). Our study employs NRI riverine flood risk products (i.e., flood loss, social vulnerability, 
community resilience) to investigate loss estimates. Figure 11 shows the census-level building values exposed to riverine flooding in this study at the top and FEMA's flood risk assessment at the bottom. Typically, more building value in the exposed flood zone is an indicator of more probable flood loss in the flood-prone area. As shown in Figure 11, values of the analyzed building stock in this study is lower than FEMA's building stock.

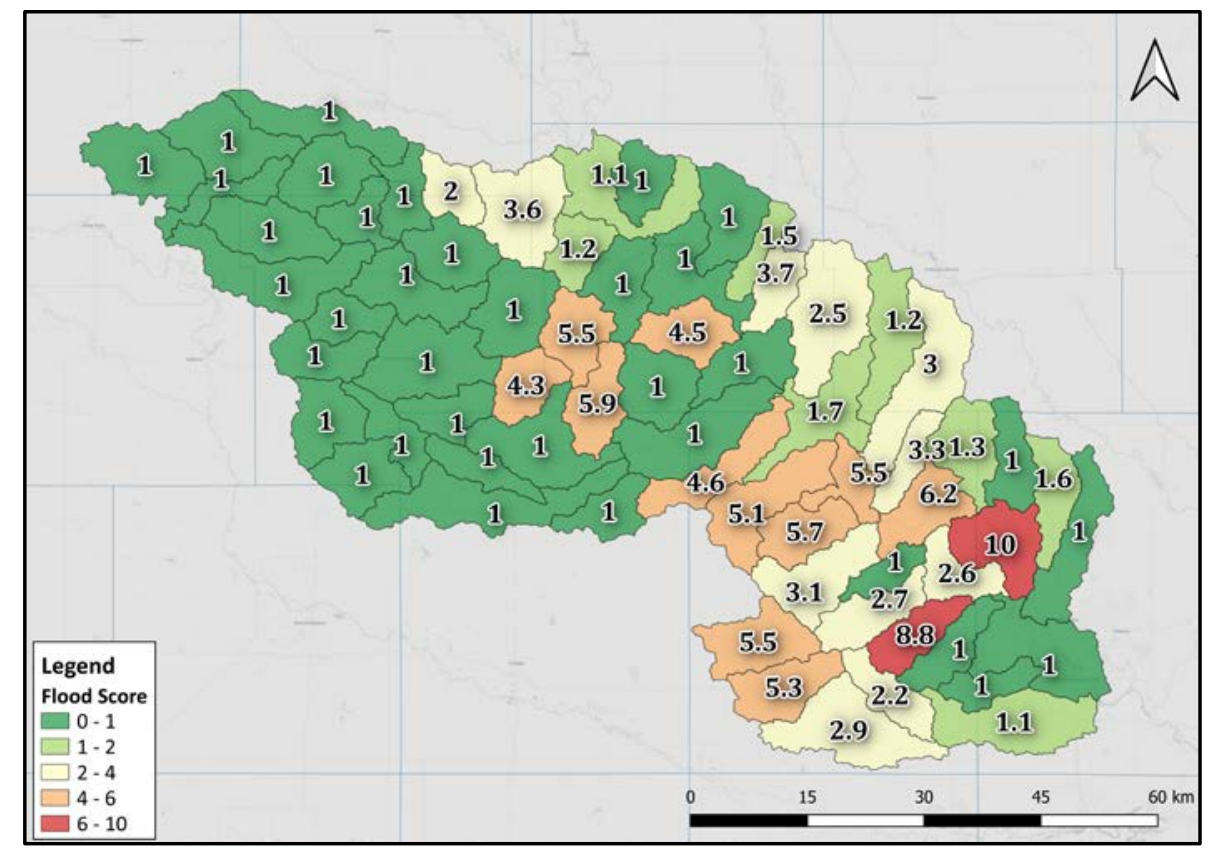

Figure 10. Watershed-level flood risk score for Middle Cedar watershed

Even though the NRI's property value dataset is large than our study dataset in most of the census-blocks, our results indicate that annualized losses are estimated to be similar in the state's western part. In the eastern part of the state, the study results suggest more flood losses, particularly in the urban communities. Our analysis shows that the flood risk is underestimated in the NRI risk outputs for communities such as Bettendorf, Burlington, Davenport, Cedar Falls, Dubuque, and Waterloo. Because the flood risk assessment is conducted at a census-block scale in the NRI, data aggregation errors might have occurred. Previous studies also addressed the same challenge of the data aggregation scale (Tate et al., 2015; Shultz, 2017). Decision-makers should be aware of the limitations of the datasets while planning new hazard mitigation efforts and informing the public about the risk. A more detailed assessment is critical to comprehend the current risk and maximize the benefits from the mitigation applications. Figure 12 provides the comparison between the risk assessment in this study (top) and FEMA's risk outputs (bottom) in census-block scale.

In Table 3, the top twenty most impacted census-blocks are listed to reflect their social vulnerability and community resilience percentile at the state and national scale. The social vulnerability and community resilience datasets are acquired from the NRI. More than half of the most exposed census-blocks are below average concerning social vulnerability. Although Iowa City and Muscatine have a relatively lower social vulnerability, the cities' community resilience is lower than other regions. Differently, two of the census-blocks of Cedar Rapids and a census-block 
of Waterloo have the highest social vulnerability in the top twenty census-blocks. However, their community resilience is higher than national and state averages. Recent studies have highlighted the relationship between social vulnerability, community resilience, and the disaster's cost (Kind et al., 2020; Sayers et al., 2018). Therefore, mitigation may need to be addressed in these censusblocks to reduce direct losses and indirect losses.

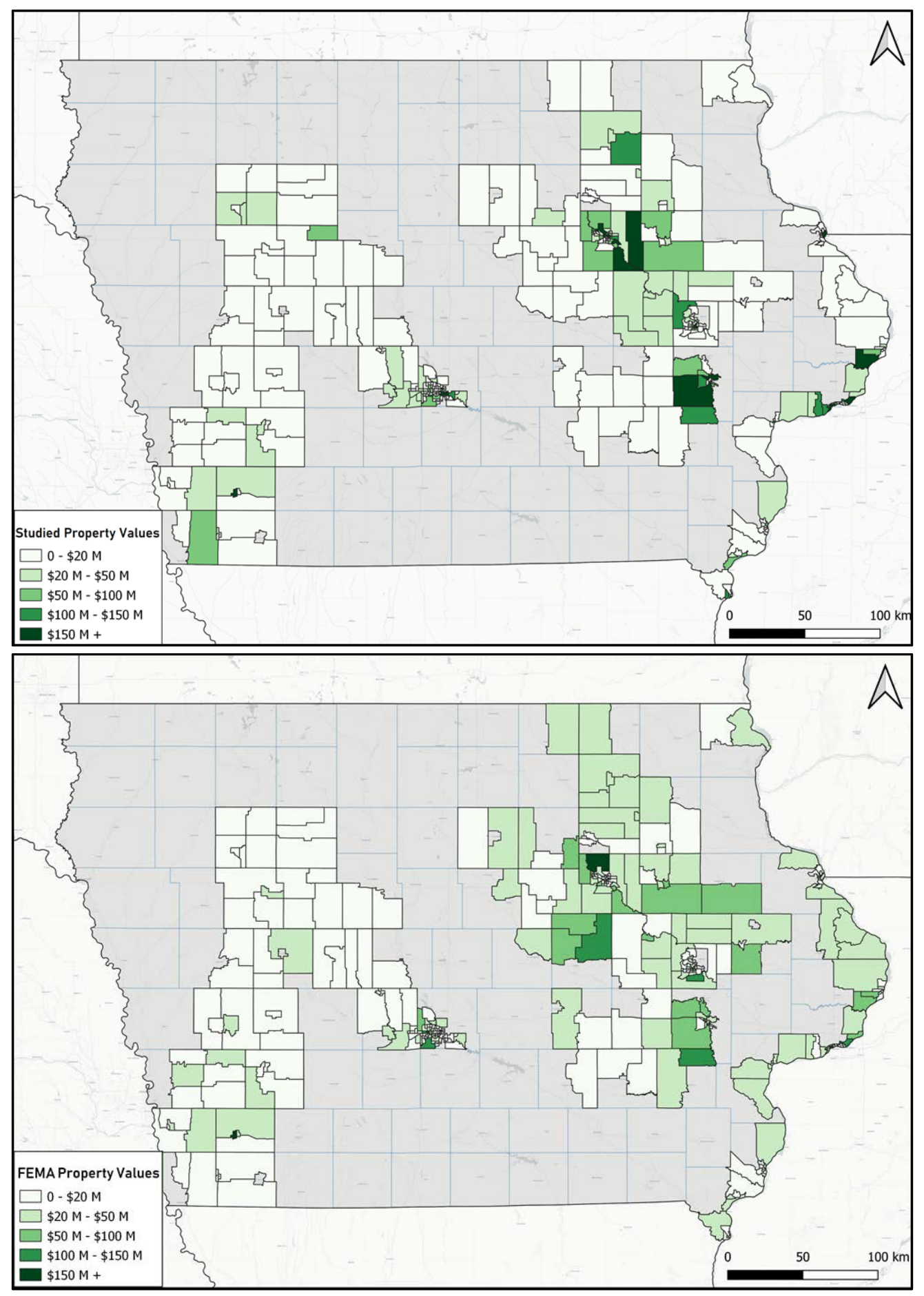

Figure 11. Property values for the study region for study dataset (top) and FEMA (bottom) 


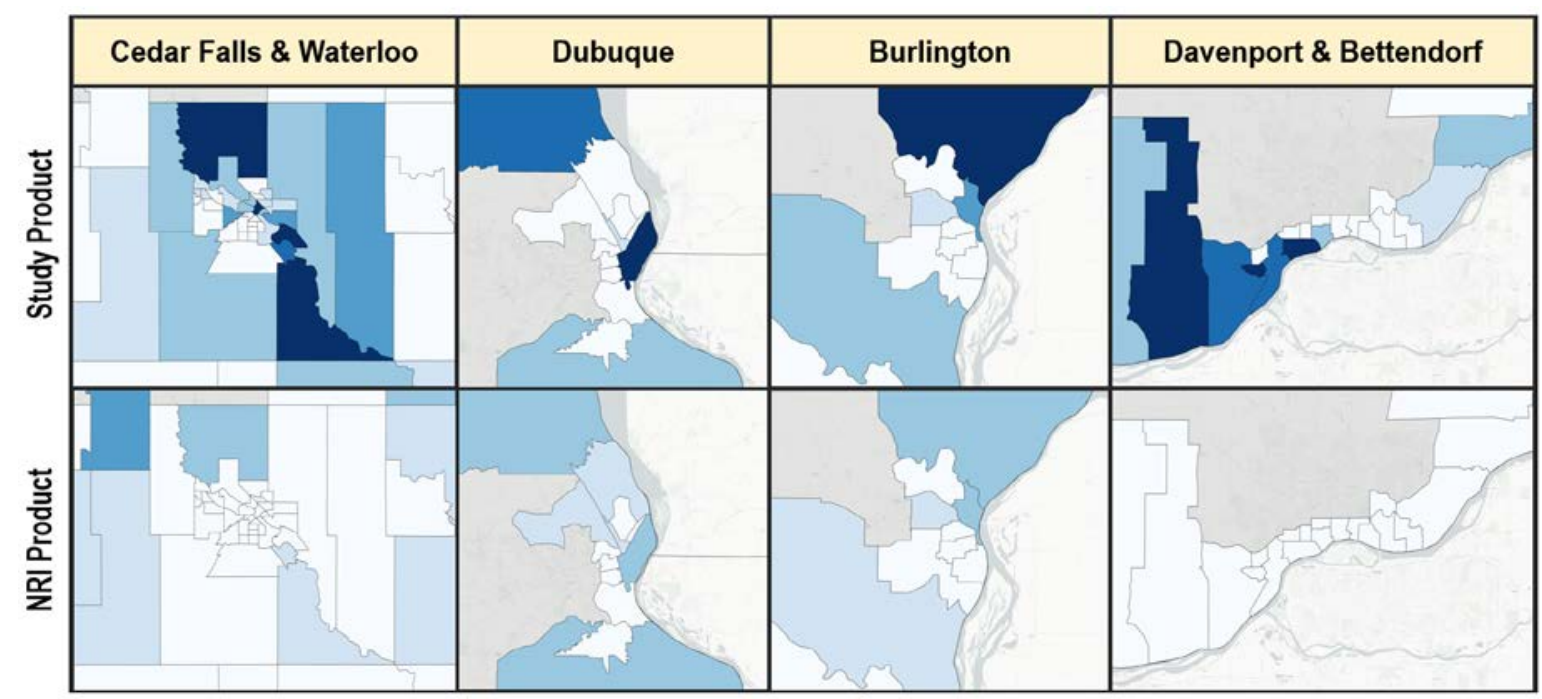

Figure 11. Average annualized loss estimate results for the study (top) and FEMA (bottom)

Table 3. Social vulnerability and community resilience percentiles for the most impacted 20 census-blocks

\begin{tabular}{|c|c|c|c|c|c|c|}
\hline \multirow[b]{2}{*}{ Census Tract } & \multirow[b]{2}{*}{ City } & \multirow[b]{2}{*}{ County } & \multicolumn{2}{|c|}{$\begin{array}{c}\text { PCTL for Social } \\
\text { Vulnerability }\end{array}$} & \multicolumn{2}{|c|}{$\begin{array}{c}\text { PCTL for Community } \\
\text { Resilience }\end{array}$} \\
\hline & & & National & State & National & State \\
\hline T19103000100 & Iowa City & Johnson & 12 & 5 & 73 & 15 \\
\hline T19113002600 & Cedar Rapids & Linn & 23 & 13 & 97 & 94 \\
\hline T19061010600 & Dubuque & Dubuque & 24 & 14 & 98 & 98 \\
\hline T19013002901 & Waterloo & Black Hawk & 26 & 16 & 94 & 82 \\
\hline T19013002902 & Waterloo & Black Hawk & 35 & 27 & 94 & 82 \\
\hline T19103000200 & Iowa City & Johnson & 40 & 36 & 73 & 15 \\
\hline T19139050900 & Muscatine & Muscatine & 41 & 38 & 75 & 17 \\
\hline T19013002000 & Waterloo & Black Hawk & 43 & 40 & 94 & 82 \\
\hline T19057001000 & Burlington & Des Moines & 46 & 44 & 88 & 58 \\
\hline T19153005100 & Des Moines & Polk & 48 & 48 & 88 & 56 \\
\hline T19013002604 & Cedar Falls & Black Hawk & 52 & 53 & 94 & 82 \\
\hline T19163010402 & Davenport & Scott & 53 & 54 & 83 & 29 \\
\hline T19061000100 & Dubuque & Dubuque & 54 & 55 & 98 & 98 \\
\hline T19163012300 & Davenport & Scott & 58 & 61 & 83 & 29 \\
\hline T19163011000 & Davenport & Scott & 61 & 66 & 83 & 29 \\
\hline T19163012400 & Davenport & Scott & 66 & 73 & 83 & 29 \\
\hline T19113001900 & Cedar Rapids & Linn County & 80 & 89 & 97 & 94 \\
\hline T19163010900 & Davenport & Scott & 83 & 91 & 83 & 29 \\
\hline T19113002700 & Cedar Rapids & Linn County & 90 & 97 & 97 & 94 \\
\hline T19013000100 & Waterloo & Black Hawk & 92 & 98 & 94 & 82 \\
\hline
\end{tabular}




\section{Conclusion}

This research presents a comprehensive large-scale flood risk assessment for the state of Iowa. Our results indicate that the eastern part of the state is the most vulnerable to direct flood losses, particularly in the Middle Cedar watershed and counties located in the Mississippi region. In the Bettendorf, Cedar Rapids, Davenport, Des Moines, and Mississippi regions, commercial flood losses are estimated to be the highest. On the other hand, residential losses are more dominant in other large communities such as Cedar Falls, Iowa City, and Waterloo. Our study reveals that the flood loss is underestimated in the NRI's outputs, particularly in large communities in the eastern part of the state such as Bettendorf, Cedar Falls, Davenport, Dubuque, and Waterloo. Because federal risk assessments are commonly used as a reference for planning and mitigation, the limitations of the NRI should be considered by decision-makers and the public. The output of this study can be used to calibrate existing flood risk assessment and improve flood mitigation decisions to maximize the benefits of the investments. The study also presents a flood risk score methodology by integrating flood damage, inundation depth, and mitigation practices. The flood risk score can support mitigation decision processes such as hazard mitigation planning, preparedness, and informing the public.

The study also analyzed FEMA's social vulnerability and community resilience products to assess the top impacted census-blocks in the State of Iowa. We found that half of these censusblocks are above average in social vulnerability compared to the state's and the nation's percentiles. In contrast, some of these communities that showed lower social vulnerability also have lower community resilience, such as Iowa City and Muscatine. Although lower community resilience may not contribute to direct losses, it may increase indirect losses. In order to reduce indirect losses, socially vulnerable and lower resilient regions must be considered for mitigation planning.

One of the challenges for the study is the lack of a standardized and centralized parcel information repository. The data is often available from local county assessors which includes a time-consuming process (data grant application, approval, etc.) for data requests. Datasets acquired from various sources also require additional work before getting ready for the loss estimation analysis. A nation-wide parcel repository could be a critical asset for local communities with limited resources for mitigation planning and implementation..

\section{References}

Agliamzanov, R., Sit, M., \& Demir, I. (2020). Hydrology@ Home: a distributed volunteer computing framework for hydrological research and applications. Journal of Hydroinformatics, 22(2), 235-248.

André, C., Monfort, D., Bouzit, M., \& Vinchon, C. (2013). Contribution of insurance data to cost assessment of coastal flood damage to residential buildings: insights gained from Johanna (2008) and Xynthia (2010) storm events. Natural Hazards and Earth System Sciences, 13(8), 2003-2012. 
Barth, N. A., Villarini, G., \& White, K. (2018). Contribution of eastern North Pacific tropical cyclones and their remnants on flooding in the western United States. International Journal of Climatology, 38(14), 5441-5446.

Blöschl, G., Hall, J., Parajka, J., Perdigão, R. A., Merz, B., Arheimer, B., ... \& Čanjevac, I. (2017). Changing climate shifts timing of European floods. Science, 357(6351), 588-590.

Brakenridge, G.R. (2020) Global Active Archive of Large Flood Events, Dartmouth Flood Observatory, University of Colorado. Retrieved online Available online: http://floodobservatory.colorado.edu/Archives/index.html (accessed 2020)

Commonwealth Scientific and Industrial Research Organisation (CSIRO) (2020). Climate and Disaster Resilience. Retrieved online Available online: https:/www.csiro.au/

Cutter, S. L., Barnes, L., Berry, M., Burton, C., Evans, E., Tate, E., \& Webb, J. (2008). A placebased model for understanding community resilience to natural disasters. Global environmental change, 18(4), 598-606.

Demir, I., Yildirim, E., Sermet, Y., \& Sit, M. A. (2018). FLOODSS: Iowa flood information system as a generalized flood cyberinfrastructure. International journal of river basin management, 16(3), 393-400.

Demir, I., Jiang, F., Walker, R. V., Parker, A. K., \& Beck, M. B. (2009, October). Information systems and social legitimacy scientific visualization of water quality. In 2009 IEEE International Conference on Systems, Man and Cybernetics (pp. 1067-1072).

Department for Environment, Food \& Rural Affairs (DEFRA) (2016). National Flood Resilience Review Retrieved online Available online: https://assets.publishing.service.gov.uk/ (accessed 2020)

Eichholtz, P., Steiner, E., \& Yönder, E. (2019). Where, When, and How Do Sophisticated Investors Respond to Flood Risk? Available at SSRN 3206257.

Ebert-Uphoff, I., Thompson, D. R., Demir, I., Gel, Y. R., Karpatne, A., Guereque, M., ... \& Smyth, P. (2017, September). A vision for the development of benchmarks to bridge geoscience and data science. In 17th International Workshop on Climate Informatics.

Emanuelsson, M. A. E., Mcintyre, N., Hunt, C. F., Mawle, R., Kitson, J., \& Voulvoulis, N. (2014). Flood risk assessment for infrastructure networks. Journal of Flood Risk Management, 7(1), 31-41.

Ewing, G., \& Demir, I. (2021). An ethical decision-making framework with serious gaming: a smart water case study on flooding. Journal of Hydroinformatics, 23(3), 466-482.

FEMA. (2009). Homeowner's Guide to Retrofitting. Six Ways to Protect Your Home From Flooding. $\quad$ Retrieved from https://www.austintexas.gov/sites/default/files/files/Watershed/flood/fema_p312_a.pdf .

FEMA, (2020). Retrieved online Available online: https:/www.fema.gov/openfema-datapage/fima-nfip-redacted-claims (accessed 2020)

FEMA, (2020). Retrieved online Available online: https://www.fema.gov/data-visualizationsummary-disaster-declarations-and-grants (accessed 2020) 
FEMA, (2021) The National Risk Index. Retrieved online Available online: https://hazards.geoplatform.gov/portal/apps/MapSeries/index.html?appid=ddf915a24fb24dc8 863eed96bc3345f8

FEMA, (2021) Risk Rating 2.0. Retrieved online Available online: https://www.fema.gov/floodinsurance/work-with-nfip/risk-rating (accessed 2021)

FEMA, (2020). Retrieved online Available online: https://www.fema.gov/datavisualization/historical-flood-risk-and-costs (accessed 2020)

Flanagan, P. X., Mahmood, R., Umphlett, N. A., Haacker, E., Ray, C., Sorensen, W., ... \& Fajman, P. (2020). A Hydrometeorological Assessment of the Historic 2019 Flood of Nebraska, Iowa, and South Dakota. Bulletin of the American Meteorological Society, 101(6), E817-E829.

Flood Factor Website (2020). Retrieved online Available online: https://floodfactor.com/state/iowa/19_fsid\#historic_flooding

Garvin, S., Hunter, K., McNally, D., Barnett, D., \& Dakin, R. (2016). Property flood resilience database: an innovative response for the insurance market. In E3S Web of Conferences (Vol. 7, p. 22002). EDP Sciences.

Gao, Y. Q., Zhou, X., \& Zhang, Z. X. (2020). Regional Flood Risk Analysis for Huaihong South Flood Control Protected Area in China using an Integrated Method. Applied Ecology and Environmental Research, 18(2), 3313-3329.

Gilles, D., Young, N., Schroeder, H., Piotrowski, J., \& Chang, Y. J. (2012). Inundation mapping initiatives of the Iowa Flood Center: State-wide coverage and detailed urban flooding analysis. Water, 4(1), 85-106.

Gouldby, B., Sayers, P., Mulet-Marti, J., Hassan, M. A. A. M., \& Benwell, D. (2008, June). A methodology for regional-scale flood risk assessment. In Proceedings of the Institution of Civil Engineers-Water Management (Vol. 161, No. 3, pp. 169-182). Thomas Telford Ltd.

Gupta, K. (2020). Challenges in developing urban flood resilience in India. Philosophical Transactions of the Royal Society A, 378(2168), 20190211.

Hallegatte, S. (2014). Economic resilience: definition and measurement. The World Bank.

Haltas, I., Yildirim, E., Oztas, F., \& Demir, I. (2020). A Comprehensive Flood Event Specification and Inventory: 1930-2020 Turkey Case Study.

Herringshaw, C. J., Stewart, T. W., Thompson, J. R., \& Anderson, P. F. (2011). Land use, stream habitat and benthic invertebrate assemblages in a highly altered Iowa watershed. The American Midland Naturalist, 165(2), 274-293.

Hipple, J. D., Drazkowski, B., \& Thorsell, P. M. (2005). Development in the Upper Mississippi Basin: 10 years after the Great Flood of 1993. Landscape and Urban Planning, 72(4), 313-323.

Hodgkins, G. A., Dudley, R. W., Archfield, S. A., \& Renard, B. (2019). Effects of climate, regulation, and urbanization on historical flood trends in the United States. Journal of Hydrology, 573, 697-709.

Huang, K., Ye, L., Chen, L., Wang, Q., Dai, L., Zhou, J., ... \& Zhang, J. (2018). Risk analysis of flood control reservoir operation considering multiple uncertainties. Journal of Hydrology, $565,672-684$. 
Jonkman, S.N., \& Schweckendiek, T. (2015). Developments in levee reliability and flood risk analysis in the Netherlands. In T. Schweckendiek, et al. (Eds.), Geotechnical safety and risk $\mathrm{V}$, proceedings of the ISGSR conference in Rotterdam (pp. 50-60). Amsterdam: IOS Press. doi:10.3233/978-1-61499-580-7-50

Khan, M. U., Mesbah, M., Ferreira, L., \& Williams, D. J. (2017). Assessment of flood risk to performance of highway pavements. In Proceedings of the Institution of Civil EngineersTransport (Vol. 170, No. 6, pp. 363-372). Thomas Telford Ltd.

Kind, J., Botzen, W. W., \& Aerts, J. C. (2020). Social vulnerability in cost-benefit analysis for flood risk management. Environment and Development Economics, 25(2), 115-134.

Lawrence, J., Reisinger, A., Mullan, B., \& Jackson, B. (2013). Exploring climate change uncertainties to support adaptive management of changing flood-risk. Environmental science \& policy, 33, 133-142.

Luu, C., Tran, H. X., Pham, B. T., Al-Ansari, N., Tran, T. Q., Duong, N. Q., ... \& Le, H. V. (2020). Framework of Spatial Flood Risk Assessment for a Case Study in Quang Binh Province, Vietnam. Sustainability, 12(7), 3058.

Mallakpour, I., \& Villarini, G. (2015). The changing nature of flooding across the central United States. Nature Climate Change, 5(3), 250-254.

Martínez-Graña, A. M., Boski, T., Goy, J. L., Zazo, C., \& Dabrio, C. J. (2016). Coastal-flood risk management in central Algarve: Vulnerability and flood risk indices (South Portugal). Ecological Indicators, 71, 302-316.

Merz, B., \& Thieken, A. H. (2004). Flood risk analysis: Concepts and challenges. Österreichische Wasser-und Abfallwirtschaft, 56(3-4), 27-34.

Merz, B., Kreibich, H., Schwarze, R., \& Thieken, A. (2010). Review article" Assessment of economic flood damage". Natural Hazards and Earth System Sciences, 10(8), 1697-1724.

Merz, B., Thieken, A., \& Kreibich, H. (2011). Quantification of socio-economic flood risks. In Flood Risk Assessment and Management (pp. 229-247). Springer, Dordrecht.

Morita, M. (2008). Flood risk analysis for determining optimal flood protection levels in urban river management. Journal of Flood Risk Management, 1(3), 142-149.

Musselman, K. N., Lehner, F., Ikeda, K., Clark, M. P., Prein, A. F., Liu, C., ... \& Rasmussen, R. (2018). Projected increases and shifts in rain-on-snow flood risk over western North America. Nature Climate Change, 8(9), 808-812.

Nofal, O. M., \& van de Lindt, J. W. (2020). Probabilistic Flood Loss Assessment at the Community Scale: Case Study of 2016 Flooding in Lumberton, North Carolina. ASCE-ASME Journal of Risk and Uncertainty in Engineering Systems, Part A: Civil Engineering, 6(2), 05020001.

Paprotny, D., Sebastian, A., Morales-Nápoles, O., \& Jonkman, S. N. (2018). Trends in flood losses in Europe over the past 150 years. Nature communications, 9(1), 1985.

Phillips, B. T., Brown, J. M., Williams, A. J., \& Plater, A. J. (2017). Combining regional and local scale coastal flood risk assessment and hazard modelling. Coastal Dynamics Conference.

Phongsapan, K., Chishtie, F., Poortinga, A., Bhandari, B., Meechaiya, C., Kunlamai, T., ... \& Markert, A. (2019). Operational flood risk index mapping for disaster risk reduction using 
Earth Observations and cloud computing technologies: a case study on Myanmar. Frontiers in Environmental Science, 7, 191.

Rogger, M., Agnoletti, M., Alaoui, A., Bathurst, J. C., Bodner, G., Borga, M., ... \& Holden, J. (2017). Land use change impacts on floods at the catchment scale: Challenges and opportunities for future research. Water resources research, 53(7), 5209-5219., G. A., Dudley, R. W., Archfield, S. A., \& Renard, B. (2019). Effects of climate, regulation, and urbanization on historical flood trends in the United States. Journal of Hydrology, 573, 697-709.

Sayers, P., Yuanyuan, L., Galloway, G., Penning-Rowsell, E., Fuxin, S., Kang, W., ... \& Le Quesne, T. (2013). Flood risk management: a strategic approach.

Sayers, P., Penning-Rowsell, E. C., \& Horritt, M. (2018). Flood vulnerability, risk, and social disadvantage: current and future patterns in the UK. Regional environmental change, 18(2), 339-352.

Schelfaut, K., Pannemans, B., Van der Craats, I., Krywkow, J., Mysiak, J., \& Cools, J. (2011). Bringing flood resilience into practice: the FREEMAN project. Environmental Science \& Policy, 14(7), 825-833.

Sebastian, A. G. (2016). Quantifying Flood Risk and Hazard in Highly Urbanized Coastal Watersheds (Doctoral dissertation) Rice University.

Seo, B. C., Keem, M., Hammond, R., Demir, I., \& Krajewski, W. F. (2019). A pilot infrastructure for searching rainfall metadata and generating rainfall product using the big data of NEXRAD. Environmental modelling \& software, 117, 69-75.

Sermet, Y., Demir, I., \& Muste, M. (2020). A serious gaming framework for decision support on hydrological hazards. Science of The Total Environment, 728, 138895.

Shultz, S. (2017). Accuracy of HAZUS general building stock data. Natural Hazards Review, 18(4), 04017012.

Sit, M., Sermet, Y., \& Demir, I. (2019). Optimized watershed delineation library for server-side and client-side web applications. Open Geospatial Data, Software and Standards, 4(1), 1-10.

Slater, L. J., \& Villarini, G. (2016). Recent trends in U.S. flood risk. Geophysical Research Letters, 43(24), 12-428.

Suarez, P., Anderson, W., Mahal, V., \& Lakshmanan, T. R. (2005). Impacts of flooding and climate change on urban transportation: A systemwide performance assessment of the Boston Metro Area. Transportation Research Part D: transport and environment, 10(3), 231-244.

Sumi, T. (2008). Designing and operating of flood retention dry dams in Japan and USA. Advances in Hydro-Science and Engineering, 8, 1768-1777.

Tapia-Silva, F. O., Itzerott, S., Foerster, S., Kuhlmann, B., \& Kreibich, H. (2011). Estimation of flood losses to agricultural crops using remote sensing. Physics and Chemistry of the Earth, Parts A/B/C, 36(7-8), 253-265.

Tate, E., Muñoz, C., \& Suchan, J. (2015). Uncertainty and sensitivity analysis of the HAZUS-MH flood model. Natural Hazards Review, 16(3), 04014030. 
Teague, A., Sermet, Y., Demir, I., \& Muste, M. (2021). A collaborative serious game for water resources planning and hazard mitigation. International Journal of Disaster Risk Reduction, 53, 101977.

The U.S. Census Bureau (2021) Retrieved online Available online: https://www.census.gov/

The United States Homeland Security (DHS) (2019). F.Y. 2019 Agency Financial Report Retrieved online Available online: https://www.dhs.gov/

UNISDR, W. (2012). Disaster risk and resilience. Thematic Think Piece, U.N. System Task Force on the Post-2015 UN Development Agenda.

Vickery, P. J., Skerlj, P. F., Lin, J., Twisdale Jr, L. A., Young, M. A., \& Lavelle, F. M. (2006). HAZUS-MH hurricane model methodology. II: Damage and loss estimation. Natural Hazards Review, 7(2), 94-103.

Vitale, C., Meijerink, S., Moccia, F. D., \& Ache, P. (2020). Urban flood resilience, a discursiveinstitutional analysis of planning practices in the Metropolitan City of Milan. Land Use Policy, 95, 104575.

Waghwala, R. K., \& Agnihotri, P. G. (2019). Flood risk assessment and resilience strategies for flood risk management: A case study of Surat City. International Journal of Disaster Risk Reduction, 40, 101155.

Wang, Y., Meng, F., Liu, H., Zhang, C., \& Fu, G. (2019). Assessing catchment scale flood resilience of urban areas using a grid cell based metric. Water research, 163, 114852.

Weber, L. J., Muste, M., Bradley, A. A., Amado, A. A., Demir, I., Drake, C. W., ... \& Thomas, N. W. (2018). The Iowa Watersheds Project: Iowa's prototype for engaging communities and professionals in watershed hazard mitigation. International journal of river basin management, 16(3), 315-328.

Wing, O. E., Bates, P. D., Smith, A. M., Sampson, C. C., Johnson, K. A., Fargione, J., \& Morefield, P. (2018). Estimates of present and future flood risk in the conterminous United States. Environmental Research Letters, 13(3), 034023.

World Bank. 2013. Building Resilience: Integrating Climate and Disaster Risk into Development. Washington, DC. (c) World Bank. Retrieved online Available online: https://openknowledge.worldbank.org/handle/10986/16639 License: CC BY 3.0 IGO

World Meteorological Organization (WMO). (2020) 2020 State of Climate Services. No. 1252. Retrieved online Available online: https://library.wmo.int/ (accessed 2020)

Xu, H., Windsor, M., Muste, M., \& Demir, I. (2020). A web-based decision support system for collaborative mitigation of multiple water-related hazards using serious gaming. Journal of environmental management, 255, 109887.

Xu, H., Demir, I., Koylu, C., \& Muste, M. (2019). A web-based geovisual analytics platform for identifying potential contributors to culvert sedimentation. Science of the Total Environment, 692, 806-817.

Yildirim, E., (2017). Hazus-MH flood loss estimation on a Web-based system. Master's Thesis. University of Iowa. 
Yildirim, E., \& Demir, I. (2019). An integrated web framework for HAZUS-MH flood loss estimation analysis. Natural Hazards, 99(1), 275-286.

Yildirim, E., \& Demir, I. (2021). An Integrated Flood Risk Assessment and Mitigation Framework: A Case Study for Middle Cedar River Basin, Iowa, U.S. International Journal of Disaster Risk Reduction, 102113. 